\title{
Treatment of Effluent by Forced Circulation Evaporator Followed By Asp in Chemical Industry
}

\author{
Mr. Umesh Shirke ${ }^{1}$, Dr. Arif Khan ${ }^{2}$ \\ ${ }^{1}$ M.Tech Student. ${ }^{2}$ Principal \\ Department of Environmental Engineering, Nuva College of Engineering \& Technology, Nagpur.
}

DOI: 10.46335/IJIES.2020.5.11.1

\begin{abstract}
Chemical Industrial waste water usually contains organic and inorganic matter in varying concentrations. Many chemical in the chemical industry are toxic, toxic, mutagenic, carcinogenic or simply almost nonbiodegradable. These effluents consist of high COD\&TDS content. The untreated chemical effluent can cause toxic effect to environment if discharged to surface water. Combination of evaporation techniques \& aerobic treatment process are found to be efficient in the removal of soluble biodegradable organic pollutants. Forced circulation evaporator is best alternative to reduce COD \& TDS by evaporation techniques up to certain limit \& ASP producing high quality effluent free of organic material and suspended solids to achieve a sustainable situation.
\end{abstract}

Keywords- industrial effluent, forced circulation evaporator, TDS \& COD, ASP.

\section{I- INTRODUCTION}

$\mathrm{C}$ hemical industry is one of the most vital of all industrial sectors due to its impact on the Environment. The wastewater generation from this industry are generally highly concentrated inorganic and organic contaminants and may contain toxic pollutants. Wastewater from chemical industries usually contains varying concentration of organic and inorganic matter. Many materials are generally toxic, carcinogenic, mutagenic or almost nonbiodegradable.

The industries identified as water polluting industries are: Sugar, Distilleries, Pulp and Paper, Tanneries, Chemicals, Dyeing and Textiles, Refineries, Food, Dairy and Beverages, Electroplating and others. The water polluting industries discharge their effluent having high organic contents measured in-terms of bio-chemical oxygen demand (BOD), and other toxic constituents like metals, organic and in-organic compounds.

To cope up with such pollutants various treatment technologies are introduced for its removal. The systems available of treating industrial effluent are based on Physico-chemical and biological principles.

In some cases when the wastewater generated is very high, no single treatment system is capable of removing the specific pollutants. Hence in this condition the combinations of system are used for reduction of pollutants. Wastewater can be characterized depending upon the nature of the process used by the industries.

\section{II- PROCESS DESCRIPTION AND METHODOLOGY}

The chemical manufacturing process involves usage of more organic and inorganic salts, which is becoming major part of high COD \& TDS. In thermal separation process, Evaporation and cooling are the common techniques used to extract available salts and generate low COD \& TDS quality effluent. It is a thermal separation or thermal concentration process. The circulation liquid is heated when it flow through the heat exchanger and then partially evaporated when the pressure is reduced in the separator, cooling the liquid to the boiling temperature, during this process, salt is removed from the bottom of the forced circulation evaporator \& Condensate effluent sent to storage tank for further treatment. Efficiency of the forced circulation evaporator significantly resulting in reduction 
of chemical oxygen demand and total dissolved solids by $90.5 \%$ and $96 \%$ respectively. Condensate liquid generated from thermal separation process sent to Effluent Treatment Plant. ASP is most convenient biological process where suspended and residual organics compound broken down. These treatment involves biological degradation of undesired products. The biological and chemical organism can be reduced up to large extent. It uses air (or oxygen) and microorganism for waste water treatment thus it is eco friendly process \& self-sustaining system. The basic principle behind all activated sludge processes is that as microorganisms grow, they form particles that clump together. These particles (floc) are allowed to settle to the bottom of the tank, leaving a relatively clear liquid free of organic material and suspended solids. ASP is suitable for organic water contains COD below 4000 ppm. It is cost effective process. The effect of different parameters like temperature, pressure can be neglected as 33 microorganisms can adapt surrounding environment up to certain extent, however it may affect the DO concentration. However DO Concentration maintain for it by supplying air. The treated effluent when satisfies the prescribed norms by $\mathrm{CPCB}$, is send to Common Effluent Treatment Plant (CETP) for Disposal.

2.1 Parameters and method of analysis: The parameters like pH, TDS (Total dissolved solids), COD (Chemical oxygen demand), were analyzed to evaluate the performance of effluent treatment plant. The analysis were carried out as per the standard methods of APHA, IWWA.

\section{III- RESULTS}

Effluent Characteristics of Force Circulation Evaporator:

Parameters of effluent generated from different chemical process before feeding to force circulation evaporator are as given below:

3.1 Results of Effluent before treatment with force circulation evaporator:

\begin{tabular}{|c|c|c|c|}
\hline No. & Parameters & Unit & Result \\
\hline 1 & $\mathrm{pH}$ & - & $6.9-8.4$ \\
\hline 2 & $\mathrm{TDS}$ & $\mathrm{mg} / \mathrm{l}$ & $32,000-38,000$ \\
\hline 3 & COD & $\mathrm{mg} / \mathrm{l}$ & $38,000-45,000$ \\
\hline
\end{tabular}

3.2 Results of Effluent after Treatment with force circulation evaporator:

\begin{tabular}{|c|c|c|c|}
\hline No. & Parameters & Unit & Result \\
\hline 1 & $\mathrm{pH}$ & - & $6.9-7.5$ \\
\hline 2 & TDS & $\mathrm{mg} / \mathrm{l}$ & $2300-5000$ \\
\hline 3 & COD & $\mathrm{mg} / \mathrm{l}$ & Below 4000 \\
\hline
\end{tabular}

At this stage the raw effluent coming from various production lines is treated with force circulation evaporator where highly concentrated COD and TDS is reduced. About $87-90 \%$ TDS reduction and about $90-95 \%$ reduction in COD achieved in this stage.

\subsection{Effluent Characteristics of Activated Sludge} Process:

\subsubsection{COD Results:}

\begin{tabular}{|c|c|c|c|c|}
\hline Months & $\begin{array}{c}\text { Equalization } \\
\text { Tank }\end{array}$ & $\begin{array}{c}\text { Primary } \\
\text { Tank }\end{array}$ & $\begin{array}{c}\text { Bioreact } \\
\text { or } \\
\text { Tank }\end{array}$ & $\begin{array}{c}\text { Final } \\
\text { Treated }\end{array}$ \\
\hline Jan & 2790.65 & 1661.65 & 568.81 & 230.52 \\
\hline Feb & 2770.36 & 1631.14 & 574.86 & 235.37 \\
\hline March & 2619.44 & 1574.72 & 589.67 & 238.18 \\
\hline Nov & 2690.97 & 1605.67 & 595.87 & 236.21 \\
\hline Dec & 2623.33 & 1569.33 & 566.87 & 228.31 \\
\hline
\end{tabular}

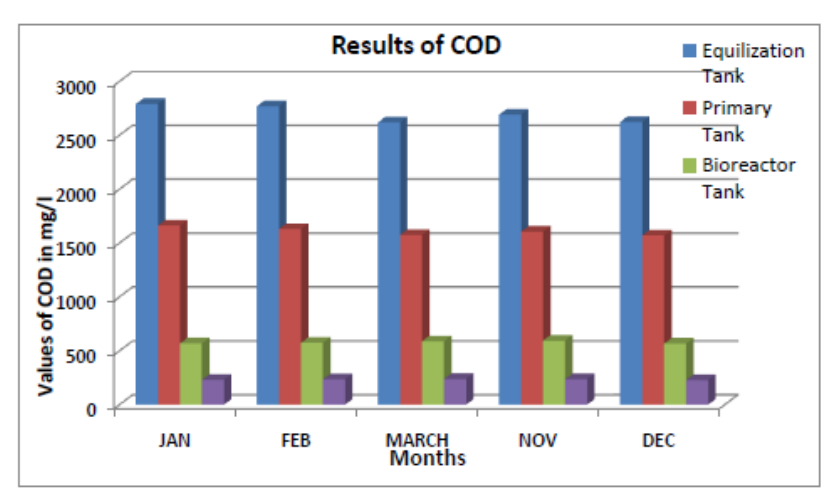

The effluent after force circulation evaporator is treated with Activated sludge process for further reduction in Parameters to achieve permissible limits as per CPCB. In this process, in primary treatment, $40-42 \%$ reduction of COD is observed whereas in secondary treatment 62-65\% reduction in COD is observed and tertiary treatment with $58-60 \%$ reduction in COD. The permissible limit for disposal for COD is $250 \mathrm{mg} / \mathrm{l}$.

\subsubsection{TDS Results:}


Table No: Results of TDS

\begin{tabular}{|c|c|c|c|c|}
\hline Months & $\begin{array}{c}\text { Equalizat } \\
\text { ion } \\
\text { Tank }\end{array}$ & $\begin{array}{c}\text { Aeration } \\
\text { Tank }\end{array}$ & $\begin{array}{c}\text { Bioreacto } \\
\mathbf{r} \\
\text { Tank }\end{array}$ & $\begin{array}{c}\text { Final } \\
\text { Treated }\end{array}$ \\
\hline Jan & 3809.19 & 2302.65 & 1835.62 & 1541.24 \\
\hline Feb & 2890.76 & 1748.50 & 1397.75 & 1143.30 \\
\hline March & 2261.26 & 1361.81 & 1084.68 & 1013.93 \\
\hline Nov & 3262.32 & 1996.15 & 1582.37 & 1300.24 \\
\hline Dec & 2580.46 & 1551.87 & 1235.99 & 1061.71 \\
\hline
\end{tabular}

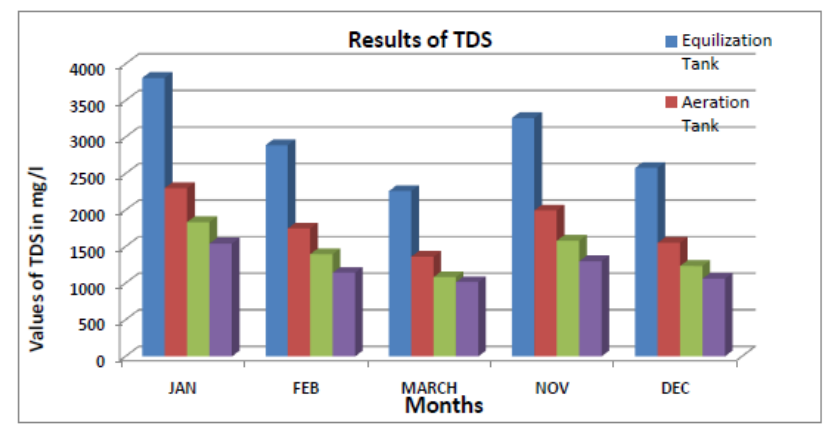

The effluent after force circulation evaporator is treated with Activated sludge process for further reduction in Parameters to achieve permissible limits as per CPCB. In this process, in primary treatment, $38-42 \%$ reduction of TDS is observed whereas in secondary treatment $18-22 \%$ reduction in TDS is observed. The permissible limit for disposal for TDS is $2100 \mathrm{mg} / \mathrm{l}$.

\section{IV- CONCLUSION}

The present study was carried out to treat the effluent from a chemical industry using FCE, which are suitable for concentrating chemical effluent comprising of high COD and TDS. The major Physico-chemical parameters COD, TDS and $\mathrm{pH}$ were analyzed for the feed and condensate of the FCE. Characterization of condensate from the FCE showed COD below 4000 ppm but above 430 ppm and TDS below 5000 ppm respectively.

As per the statutory provision / design specification, the condensate should have COD and TDS values below 250 ppm and 2100 ppm respectively. This showed the performance of thermal separation process.

After this treatment, ASP is used for significantly effecting in reduction of COD, TDS and $\mathrm{pH}$ which satisfies the permissible limits as per statutory provisions.

And hence combination of FCE (thermal separation process) followed by Activated sludge process is found effective to minimize the pollutants from wastewater.

\section{REFERENCES}

[1] FarshadFarahbod, DariushMowla, M.R. Jafari Nasr and Mohammad Soltanieh, -Experimental study of forced circulation evaporator in zero discharge desalination processl, Elsevier, Desalination · January (2011).

[2] AndrasJozsefToth, EnikoHaaz, BotondSzilagyi, Tibor Nagy, AriellaJankaTarjani, Daniel Fozer, Anita Andre, Nora Valentinyi, Szabolcs Solti and Peter Mizsey, -COD reduction of process wastewater with vacuum evaporationl, published by De Gruyter, Waste Treatment and Recovery, Vol. 3, pp 1-7, (2018).

[3] G. Mugaishudeen, A.S. PeriasamyManikandan and T. Ravi Kannan, -Experimental study of Triple Effect Forced Circulation Evaporator at Perundurai Common Effluent Treatment Plant\|, J. Acad. Indus. Res., Vol. 1(12), May (2013).

[4] Olga V. Vysokomornayaa, Julia E. Balakhnina and M. V. Shikhman, -THERMAL TREATMENT OF INDUSTRIAL WASTEWATER\|, EDP Sciences, (2015).

[5] Mohamed Osman Awaleh and YoussoufDjibrilSoubaneh, -Waste Water Treatment in Chemical Industries: The Concept and Current Technologiesl, Hydrol Current Reseach,( 2014). Environmental Engineering by GERARD KIELY.

[6] Waste water treatment in chemical industries: the concept and chemical technologies By Mohamed Osman Awaleh, YoussoufDjbrillSoubaneh (Review Paper).

[7] Treatment technologies for organic waste water by chunlizheng, Ling Zhao \& An Li.

[8] Noval method for the removal of organic halogens from process waste waters enabling Water reuse. (Review Paper).

[9] Evaporation - A Waste water treatment alternative by Tom M. Pankratz) ( Review Paper). Chemical Industry, Butibori MIDC, Nagpur.

[10] Thermal Treatment of Industrial waste water treatment By GEA WiegandGmbh process Process engineering, Germany.

[11] Improving the efficiency of multiple effect evaporator to treat effluent from Pharmaceutical industry.(International Journal).

[12] Guidelines on techno - economic feasibility of implementation of zero liquid discharge (ZLD) for water polluting industries (CPCB Govt.of India) 